\title{
Yellow nail syndrome resulting from cardiac mitral valve replacement
}

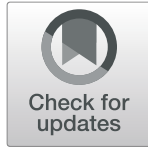

Hossein Sarmast ${ }^{*}$ and Ahmad Takriti ${ }^{2}$

\begin{abstract}
Background: Yellow nail syndrome is a rare disease with unknown etiology, Attributed to functional anomalies or disturbance in lymphatic drainage. This condition is characterized by triad of nail discoloration, respiratory or intrathoracic manifestations and lymphedema.

Case presentation: Twenty days after mitral valve replacement for severe rheumatic mitral valve stenosis, 39 years old woman presented with face tenderness and hearing problems besides stuffy and clogged nose and underwent routin rhinosinusitis therapy. She came back to ears, nose and throat service with persistent rhinosinusitis as well as relapsing preoperative couphs and dyspnea besides lower extremities edema and toenails discoloration. After some modulations of treatment, she was introduced to pulmonary clinic on post -operative day $=30$. Chest $x$ ray showed a lot of left pleural effusion then she was returned to our service (cardiac surgery) on post- operative day $=33$. The pigtail catheter was secured and we attained a significant amount of milky fluid which conformed with chylothorax. Finally Yellow nail syndrome was diagnosed with her on post-operative day $=35$. Early conservative therapy such as bed rest, legs massage, low fat diet with medium chain triglycerides, diuretics, bronchodilator inhaler was not be able to satisfy us (chylous out put $>$ $330 \mathrm{cc} / \mathrm{d}$ ). Therefore the catheter replacement with chest tube was carried out followed by pleurodesis using Talc and doxycycline besides transition of oral intake to total parentral nutrition and vitamine E supplement, on post - operative day $=41$. After that chylous leakage gradually subsided and patient was discharged to home on post- operative day $=47$. At 4 weeks follow ups, chest $x$ ray was clear without effusion and nails discoloration and legs lymphedema resolved.

Conclusion: We reported the third post cardiac surgery Yellow nail syndrome which is an unclear entity with a set of associated signs and symptoms. Two prior reports involved with coronary artery bypass graft whereas we performed mitral valve replacement. In angiogram thoracic duct was not identified so that it seems post cardiac surgery Yellow nail the syndrome has iatrogenic origin due to the thoracic duct or its tributaries injury and requires meticulous assessment and management.
\end{abstract}

Keywords: Yellow nail syndrome, Mitral valve replacement, Thoracic duct injury, Chylothorax, Pleurodesis, Pleural effusion, Total parentral nutrition, lymphedema

\section{Background}

Yellow nail syndrome (YNS) is an idiopathic rare condition attributed to functional abnormalities of lymphatic drainage. It is characterized by three cardinal signs related to yellow nails, lymphedema and respiratory manifestations [1]. That yellowing represents a subset of chromonychia, defined as

\footnotetext{
* Correspondence: abcmoghim@gmail.com

${ }^{1}$ Cardiovascular surgery in cardiac surgery hospital of Damascus university,

Mouasat Square, Omar ben Abdulaziz Street, Damascus, Syria

Full list of author information is available at the end of the article
}

pathological nail discoloration, especially xanthonychia (yellow nail coloration). It is a syndrome that associated with conditions as different as diseases implicating the lymphatic system, autoimmune diseases or cancers $[2,3]$. The first case of YNS was probably reported by Heller in 1927 [4], but Samman and White described the first series of patients with YNS accompanied by lymphedema in 1964 [5]. Whose report consisted of 13 patients whom had slow measured nail growth associated with nail discoloration ranging from pale yellow to dark greenish [6].

(C) The Author(s). 2019 Open Access This article is distributed under the terms of the Creative Commons Attribution 4.0 International License (http://creativecommons.org/licenses/by/4.0/), which permits unrestricted use, distribution, and 
According to the information comes from a databases called HPO, the most manifestations that may be in as high as $80-99 \%$ of patients are: Bronchiectasis, nail dysplasia, lymphatic vessels hypoplasia, lymphedema and yellow nails followed by couph, dyspnea, pleuritis, RRI and rhinosinusitis in $30-79 \%$ of patients [7, 8]. Emerson added pleural effusion to the diagnostic criteria [9]. Although two criteria from first group are required to diagnosis, it is difficult to call the entity YNS without nail discoloration. In addition to being yellow, nails may lack cuticle [10, 11], grow very slowly and become detached (onycholysis) [12-14]. Respiratory problems include chronic couph, bronchiectasis and pleural effusion. The complete Triad is present only in $27-69 \%$ of patients [15-17]. YNS often occurs in adults (age $>50$ years) with no sex predominance [18]. Estimated prevalence is $<1 / 10000000[19,20]$. YNS in pediatrics is very rare $[21,22]$.

\section{Case presentation}

A 39- years old multiparous woman has suffered from mild MS for 10 years, as a result of childhood bacterial tonsilopharyngitis (rheumatic MS). The first attacks of symptoms appeared in her last year of second decade, during her second pregnancy. Her chief complaint was exertional dyspnea. Two - dimensional echocardiography (2D-ECG) revealed a decreased mitral valve area $(1.5 \mathrm{~cm} 2)$. She had no other medical conditions and her past medical history included nothing else of note. Recently the symptoms worsened and she began to experience dyspnea in ordinary activities, AF and hemoptesia (hemoptysis). 2D-ECG positive findings were: critical diminished mitral valve area $(0.8 \mathrm{~cm} 2)$, left atrial enlargement without any organized clot attachment, thickened leaflets, commissural and subvalvular fussions and mean diastolic pressure gradient across valve $=12 \mathrm{mmHg}$. She was scheduled for MVR with mechanical prosthesis. Open cardiac surgery with $\mathrm{CPB}$ using bicaval connulation was carried out. Early post-operative course was uneventful and she was discharged to home on POD $=7$ with warfarin prescription without any prohibition about taking it, since she had completed her family members. She felt face tenderness and hearing problems besides stuffy and clogged nose on POD $=20$. She underwent ENT consultation and based on the clinical and paraclinical finding, met ARS diagnosis (Fig. 1). As soon as an antihistamine, anticongestion and macrolide antibiotic was initiated. She came back to ENT service with persistent ARS as well as relapsing preoperative couphs and dyspnea besides lower extremities edema (Fig. 2) and toenails discoloration (Fig. 3). After some modulations of therapeutic drugs, she was

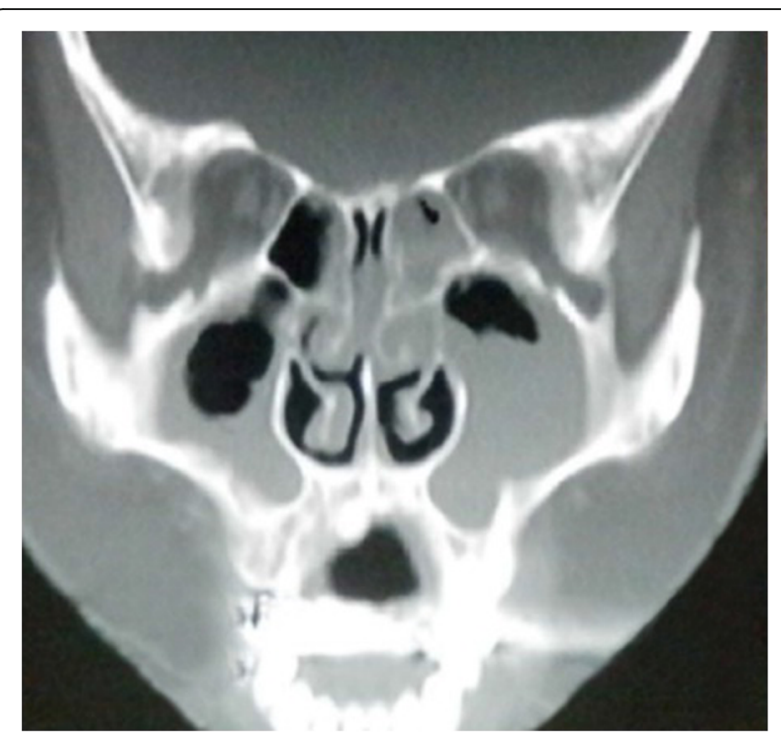

Fig. 1 Sinuses computed tomographic scan of 39 years old woman after cardiac surgery. Sinuses imaging showed acute rhinosinusitis \& homogenous parasinuses densities 20 days after miral valve replacement

referred to pulmonary clinic on $\mathrm{POD}=30$. CXR confirmed a significant left pleural effusion (Fig. 4) and she was readmitted in our service while taking lasix and SABAs (albuterol inhaler) in addition to aforementioned medicines on $\mathrm{POD}=33$. Immediately a pigtail catheter was secured with the purpose of both assessment and management. At first the fluid was bloody then became milky. Finally we attained 1850 cc frankly white fluid. Bedside ether test revealed the presence of fat which was confirmed by lab study (triglycerides $=1750 \mathrm{mg} / \mathrm{dl}$ chylomicron). We encountered with a patient who had different signs such as chylothorax, lymphedema and yellow discoloration of toenails. After dermatologist consultation we arrived at Yellow Nail Syndrome on POD $=35$. Immediately conservative treatment was taken place such as bed rest, massage and compression therapy of legs using garments, restricted diet consist of high protein low fat with medium chain triglycerides and octreotide. Since the decline of chylous drainage was unsatisfied $(330 \mathrm{cc} / \mathrm{d})$, we exchanged the pigtail catheter with an appropriate size chest tube and TPN was initiated. Then talc and doxycycline pleurodesis was carried out besides Vitamine $\mathrm{E}$ supplement on $\mathrm{POD}=41$. Fortunately chest tube output substantially decreased, allowing transition to low fat oral intake diet on POD $=45$. Chest tube was removed and the patient was discharged on $\mathrm{POD}=47$. At 4 weeks follow ups, CXR was clear without effusion and nails discoloration and legs lymphedema resolved. 


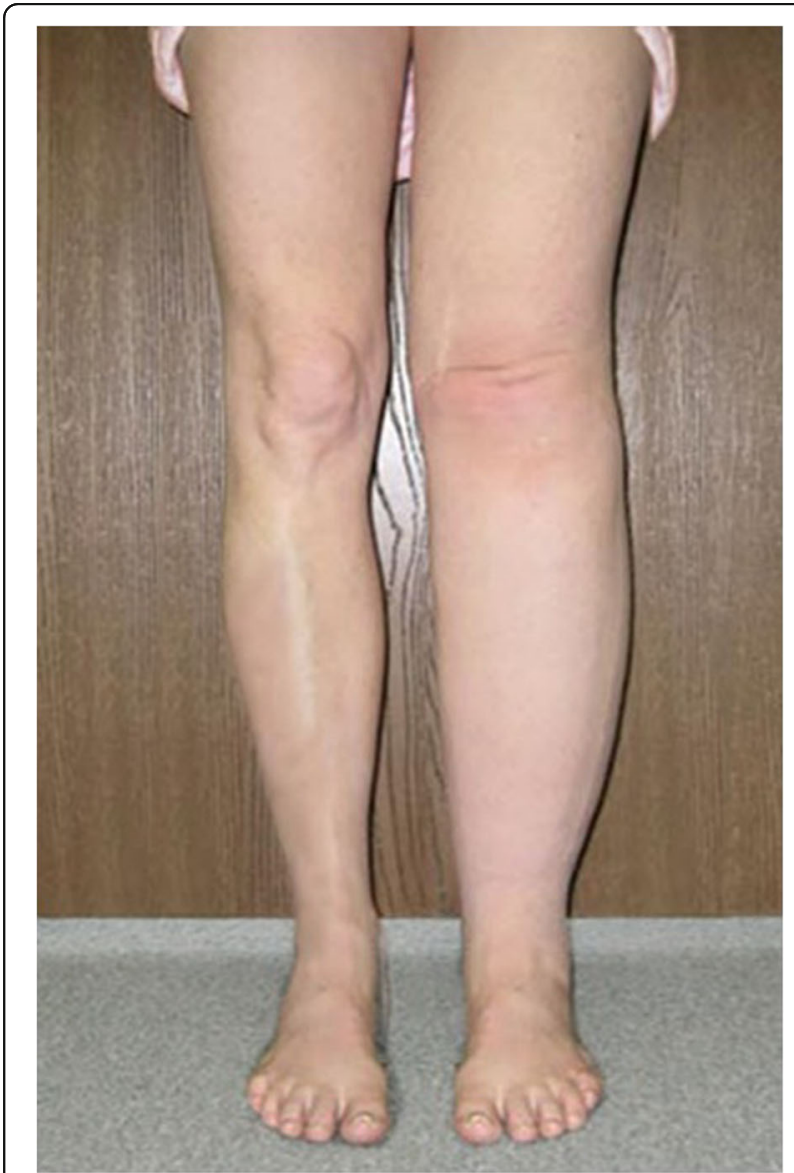

Fig. 2 Lower extremities photograph of 39 years old woman after cardiac surgery. Photograph of legs showed bilateral lymphedema (specially in the left side) conforms to Campisi clinical stage two degree, 30 days after miral valve replacement

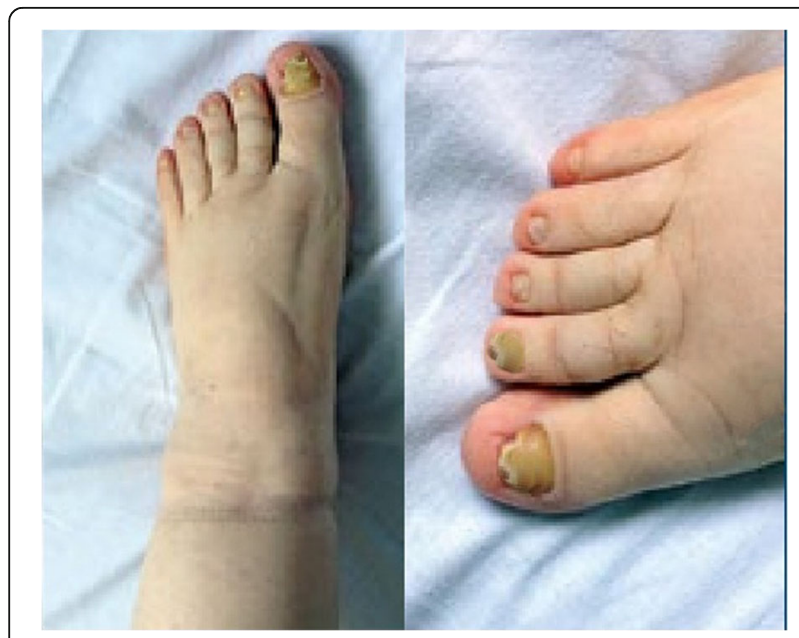

Fig. 3 Yellow toenails discoloration in 39 years old woman after cardiac surgery. 30 ays after cardiac mitral valve replacement, toenails began to yellowish discoloration, onycholysis, hyperkeratosis and disappearance of the Lunula and Cuticle

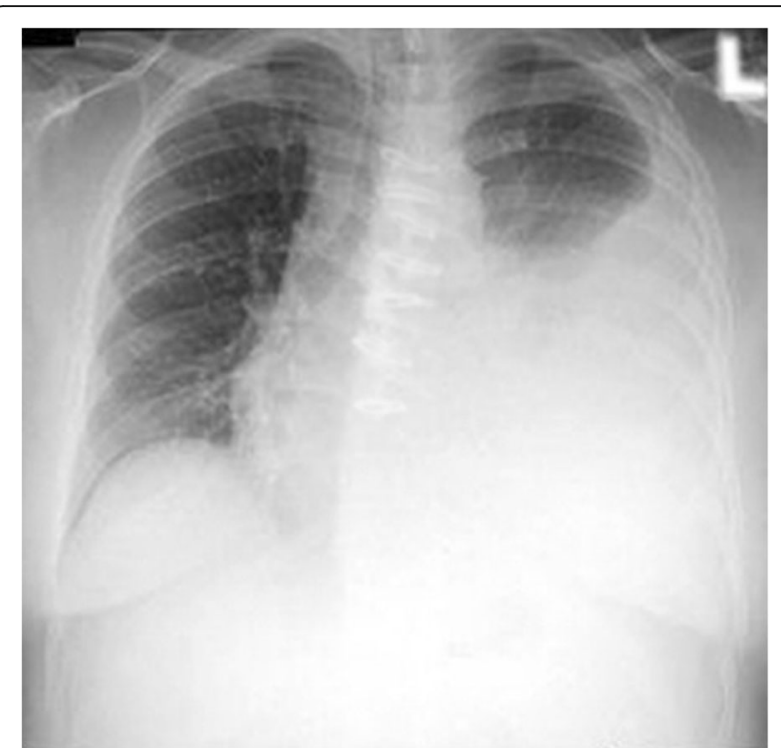

Fig. 4 Pleural effusion detected by Chest $X$ ray in 39 years old woman after cardiac surgery. Chest imaging showed a larg amount of left pleural cavity effusion, 30 days replacement after miral valve

\section{Discussion and conclusions}

YNS has remained vague entity owing to lack of information about this very rare condition. There are little available data determining exact prevalence of YNS, as fewer than 400 cases have been published in the literature. Although two instances of familial cases have already been reported that in one sample, two siblings and in the other example, four offsprings during two generations had YNS [23, 24], the very few reported familial cases mimic a dominant inheritance pattern, which is not supported by any genetic evidence. In the other words, it has not been suggested any genetic link $[25,26]$. It often occurs on its own even though is occasionally associated with autoimmune disease [27], lymphatic disease or cancers immunodeficiency disorders, such as common variable immunodeficiency, combined T- and B-cell deficiency [28, 29], Guillain-Barré syndrome [30], nephritic syndrome [31, 32], Hashimoto's thyroiditis, severe hypothyroidism or hyperthyroidism [33, 34], xanthogranulomatous pyelonephritis [35] and rheumatoid arthritis even without thiol-analog use [36]. Very rare ocular involvement has been reported: chemosis, corneal micropannus (vascularized sheet of fibroustissue overlying the cornea), eyelid lymphedema, thickened conjunctiva [37]. Anecdotal associations have also been described: anhydrosis, pectus excavatum, eosinophilia-myalgia syndrome, bullous stomatitis, sarcoidosis and Raynaud's phenomenon, cerebralaneurysm and pancytopenia. YNS is very rarely associated with primary 
intestinal lymphangiectasia (Waldmann's disease) (OMIM 152800, ORPHA90362) or lymphedema - distichiasis syndrome (OMIM 153400, ORPHA33001), suggesting that these entities have overlapping characteristics, including lymphatic impairment [38, 39]. YNS treatment is not codified. YNS may resolve in few months without treatment [40] or, when it is a paraneoplastic syndrome, after cancer therapy [41]. Symptomatic treatments are prescribed. Patients may receive antibiotics for acute exacerbation of bronchiectasia, whereas, for patients with poor symptom control and/orrecurrent exacerbations, low-dose antibiotic prophylaxis, such as oral azithromycin (usually $250 \mathrm{mg} 3$ times/week), achieved attenuation of chest symptoms for the majority of them. Physiotherapy training (postural drainage, chest physiotherapy, flutter valve), combined or not with antibiotic prophylaxis, is also prescribed to help patients self-manage their chronic expectoration. Vaccinations against flu and pneumococci are strongly recommended. Surgical intervention of recurrent and/ or large pleural effusions is useful: decortication/ pleurectomy, pleurodesis (talc, picibanil quinacrine) and pleural-peritoneal shunts were the most effective treatments of symptomatic pleural effusions with, respectively, 89,82 and $67 \%$ partial or complete responses [42, 43]. Octreotide, a somatostatin analog, was also used to treat YNS pleural effusions or chylous ascites and lymphedema, and generated positive responses [44-47]. We reported the third post cardiac surgery YNS. The first was reported in 2009 and an 80 years old male presented with YNS after CABG. The second report in 2018, belongs to a 62 years old man who endured CABG too and after that suffered from YNS. In both of them, there was coexistence regarding the LIMA harvesting and chylothorax (involving 81\%), suspiciously owing to tight proximity between LIMA and thoracic duct. How is about our case? Our operation nowise correlated with LIMA. We don't have any information about patient lymphatic system prior to the operation whether it was normal or aberrantly abnormal [48-52]. In our case the lymphangiogram demonstrated diffused abnormal indocyanine pattern in lower extremities especially on the left side but was not be able to identify the cycterna chyli and thoracic duct while showed sparse droplets of lipidol in left pleural cavity without any apparent leakage site (Fig. 5). On the other hand, doppler echocardiography precluded possibility of central venous embolization. All of the aforementioned evident findings are saying that, damage to the thoracic duct or lymphatic vessels is undertaken unless proven otherwise. According to the observations in majority of series, post thoracotomic chylothorax has been reported in the frequency of $0.2 \%$ [52-57].

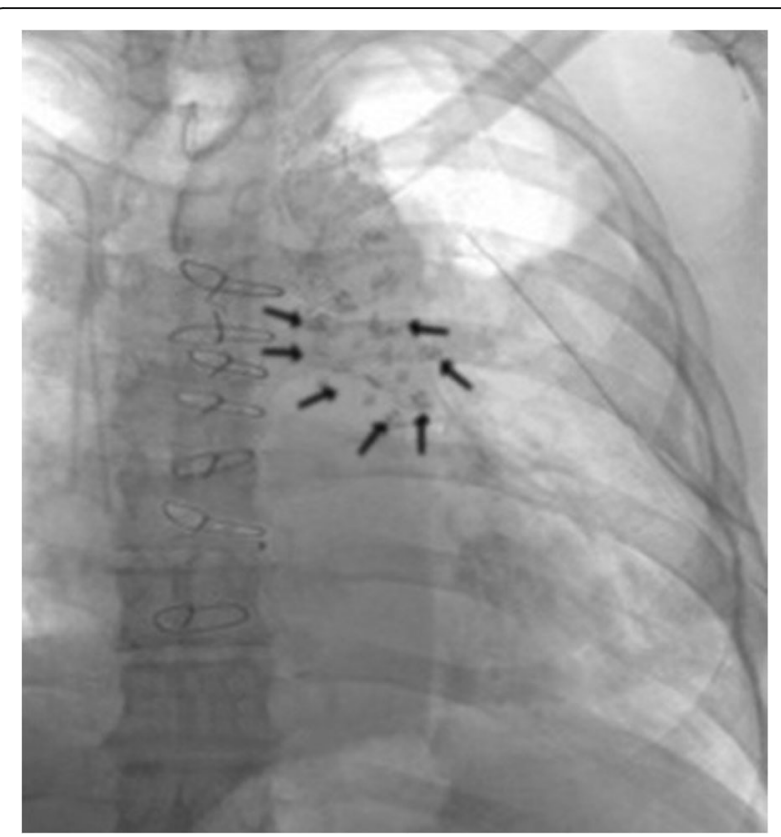

Fig. 5 Lipidol droplets clarification by lymphangiogram for assessment the ethiology of post cardiac surgery pleural effusion in 39 years old woman. Lymphangiogram Demonstrated free contrast patches in the mediastinum without detecting of cycterna chili and thoracic duct, 41 days after cardiac mitral valve replacement

Blalock and coworkers for the first time noted chylothorax following SVC ligation in 1936 . Then other surgeons observed similar findings (chylothrax) after surgical corrections such as: aortic coarctation, BTS, vascular slings, PDA, TOF, TS, VSD and APVC. Nobody other than two authors has reported full blown post cardiac surgery YNS and our report is third.

\section{Abbreviations}

2D-ECG: Two dimensional echocardiography; APVC: Anomalous pulmonary venous; ARS: Acute rhinosinusitis; BTS: Blalock-taussing shunt;

CABG: Coronary artery bypass grafting connection; CXR: Chest $X$ ray; ENT: Ears, nose and throat; HPO: Human phenotype ontology; LIMA: Left internal mammary; MS: Mitral stenosis; MVR: Mitral valve replacement; PDA: Patent ductus arteriosus; POD: Post-operative day; RRl: Recurrent respiratory infection; SABAs: Short - acting beta agonists; SVC: Superior vena cava; TOF: Tetralogy of fallot; TS: Tricuspid stenosis; VSD: Ventricular septal defect; YNS: Yellow nail syndrome

\section{Acknowledgements}

The authors wish to thank: Professor Zahra Sepehrmanesh, Dr. Soroush Sarmast \& Dr. Behina Sarmast; for their assistance in this study. Also Dr. Kevin Brady \& Dr. Fariba Brady from the USA state of New Jersey, For their editorial assistance.

\section{Funding}

As we are from lower income country, the processing charge has been waived.

\section{Availability of data and materials}

The datasets during the current study available from the corresponding author on reasonable request and for this purpose, the author received written consent from patient. 


\section{Authors' contributions}

Both authors have contributed to the conception \& writing the manuscript as well as have approved to the submission of the manuscript.

\section{Ethics approval and consent to participate}

In 2018, the ethics committee was held in the cardiac surgery center hospital of Damascus university and Department review board approval to publish a case report study entitled "Yellow nail syndrome resulting from cardiac mitral valve replacement " was obtained. As well as written consent was received from patient.

\section{Consent for publication}

Written consent for publication was obtained from patient.

\section{Competing interests}

The authors declare that they have no competing interests.

\section{Publisher's Note}

Springer Nature remains neutral with regard to jurisdictional claims in published maps and institutional affiliations.

\section{Author details}

${ }^{1}$ Cardiovascular surgery in cardiac surgery hospital of Damascus university, Mouasat Square, Omar ben Abdulaziz Street, Damascus, Syria. ${ }^{2}$ Department in cardiac surgery hospital of Damascus university, Damascus, Syria.

Received: 21 November 2018 Accepted: 1 April 2019

Published online: 11 April 2019

\section{References}

1. Hiller E, Rosenow EC 3rd, Olsen AM. Pulmonary manifestations of the yellow nail syndrome. Chest. 1972;61:452-8. https://doi.org/10.1378/chest.61.5.452.

2. Hoque SR, Mansour S, Mortimer PS. Yellow nail syndrome: not a genetic disorder? Eleven new cases and a review of the literature. Br J Dermatol. 2007;156:1230-4. https://doi.org/10.1111/j.1365-2133.2007.07894.x.

3. Maldonado F, Tazelaar HD, Wang CW, Ryu JH. Yellow nail syndrome: analysis of 41 consecutive patients. Chest. 2008;134:375-81. https://doi.org/ 10.1378/chest.08-0137.

4. Heller J. Die Krankheiten der Nagel. In: Jadassohn's Handbuch der Haut und Geschlechtskrankheiten, vol. 13 part 2. Berlin: Julius Springer; 1927. p. 423.

5. Samman PD, White WF. The yellow nail syndrome. Br J Dermatol. 1964;76: 153-7. https://doi.org/10.1111/j.1365-2133.1964.tb14499.x.

6. Baran R. Pigmentations of the nails (chromonychia). J Dermatol Surg Oncol. 1978:4:250-4.

7. Woodfield G, Nisbet M, Jacob J, et al. Bronchiectasis in yellow nail syndrome. Respirology. 2017;22:101-7.

8. Imadojemu S, Rubin A. Dramatic improvement of yellow nail syndrome with a combination of intralesional triamcinolone, fluconazole, and sinusitis management. Int J Dermatol. 2015;54:497-9.

9. Emerson PA. Yellow nails, lymphoedema, and pleural effusions. Thorax. 1966;21:247-53.

10. Stosiek N, Peters KP, Hiller D, Riedl B, Hornstein OP. Yellow nail syndrome in a patient with mycosis fungoides. J Am Acad Dermatol. 1993;28:792-4. https://doi.org/10.1016/S0190-9622(09)80277-6.

11. De Coste SD, Imber MJ, Baden HP. Yellow nail syndrome. J Am Acad Dermatol. 1990;22:608-11.

12. Holzberg M. The nail in systemic disease. In: Baran R, de Berker DAR, Holzberg M, Thomas L, editors. Baran and Dawber's diseases of the nails and their management. 4th ed. Oxford: Wiley-Blackwell; 2012. p. 328-30.

13. Venencie PY, Dicken $\mathrm{CH}$. Yellow nail syndrome: report of five cases. J Am Acad Dermatol. 1984;10:187-92. https://doi.org/10.1016/S01909622(84)70021-1

14. Moffitt DL, de Berker DA. Yellow nail syndrome: the nail that grows half as fast grows twice as thick. Clin Exp Dermatol. 2000;25:21-3. https://doi.org/ 10.1046/j.1365-2230.2000.00563.x

15. Piraccini BM, Urciuoli B, Starace $M$, Tosti A, Balestri R. Yellow nail syndrome: clinical experience in a series of 21 patients. J Dtsch Dermatol Ges. 2014;12: 131-7. https://doi.org/10.1111/ddg.12216.

16. Nordkild P, Kromann-Andersen H, Struve-Christensen E. Yellow nail syndrome - the triad of yellow nails, lymphoedema, and pleural effusions. A review of the literature and a case report. Acta Med Scand. 1986;219:221-7.
17. Varney VA, Cumberworth V, Sudderick R, Durham SR, Mackay IS. Rhinitis, sinusitis and the yellow nail syndrome: a review of symptoms and response to treatment in 17 patients. Clin Otolaryngol Allied Sci. 1994;19:237-40. https://doi.org/10.1111/j.1365-73.1994.tb01222.x.

18. Pavlidakey GP, Hashimoto K, Blum D. Yellow nail syndrome. J Am Acad Dermatol. 1984;11:509-12. https://doi.org/10.1016/S0190-9622(84)70201-5.

19. Magid M, Esterly NB, Prendiville J, Fujisaki C. The yellow nail syndrome in an 8- year-old girl. Pediatr Dermatol. 1987;4:90-3. https://doi.org/10.1111/j.15251470.1987.tb00758.x

20. Paradisis M, Van Asperen P. Yellow nail syndrome in infancy. J Paediatr Child Health. 1997;33:454-7. https://doi.org/10.1111/j.1440-1754.1997.tb01642.x.

21. Göçmen A, Küçükosmanoglu O, Kiper N, Karaduman A, Ozçelik U. Yellow nail syndrome in 10-year-old girl. Turk J Pediatr. 1997;39:105-9.

22. Yalçin E, Dogru D, Gönç EN, Cetinkaya A, Kiper N. Yellow nail syndrome in an infant presenting with lymphedema of the eyelids and pleural effusion. Clin Pediatr (Phila). 2004;43:569-72.

23. Wells GC. Yellow nail syndrome with familial primary hypoplasia of lymphatics, manifest late in life. Proc Royal Soc Med. 1966;59:447.

24. Lambert EM, Dziura J, Kauls L, Mercurio M, Antaya RJ. Yellow nail syndrome in three siblings: a randomized double-blind trial of topical vitamin E. Pediatr Dermatol. 2006:23:390-5. https://doi.org/10.1111/j.1525-1470.2006.00251.

25. Razi E. Familial yellow nail syndrome. Dermatol Online J. 2006;12:15.

26. Kamatani M, Rai A, Hen H, Hayashi K, Aoki T, Umeyama K, et al. Yellow nail syndrome associated with mental retardation in two siblings. $\mathrm{Br} J$ Dermatol. 1978;99:329-33. https://doi.org/10.1111/j.1365-2133.1978.tb02005.x.

27. Vignes S, Carcelain G. Increased surface receptor Fas (CD95) levels on CD4+ lymphocytes in patients with primary intestinal lymphangiectasia. Scand J Gastroenterol. 2009;44:252-6. https://doi.org/10.1080/00365520802321220.

28. Gupta S, Samra D, Yel L, Agrawal S. T and B cell deficiency associated with yellow nail syndrome. Scand J Immunol. 2012;75:329-35. https://doi.org/10. 1111/j.1365-3083.2011.02653.x.

29. Siegelman SS, Heckman BH, Hasson J. Lymphedema, pleural effusions and yellow nails: associated immunologic deficiency. Dis Chest. 1969;56:114-7. https://doi.org/10.1378/chest.56.2.114

30. Woollons A, Darley CR. Yellow nail syndrome following Guillain-Barré syndrome. Clin Exp Dermatol. 1997;22:253-4. https://doi.org/10.1111/j.13652230.1997.tb01084.x

31. Cockram CS, Richards P. Yellow nails and nephrotic syndrome. Br J Dermatol. 1979;101:707-9. https://doi.org/10.1111/j.1365-2133.1979.tb05651.x.

32. Sakiyama T, Shimizu T, Funakoshi T, Saito M. Case of yellow nail syndrome accompanied by nephrotic syndrome. J Dermatol. 2016;43:585-6. https:// doi.org/10.1111/1346-8138.13239.

33. Dilley JJ, Kierland RR, Randall RV, Shick RM. Primary lymphedema associated with yellow nails and pleural effusions. JAMA. 1968;204:670-3. https://doi. org/10.1001/jama.1968.03140210024005.

34. Noël-Savina E, Paleiron N, Leroyer C, Descourt R. Découverte d'un syndrome des ongles jaunes lors d'une insuffisance thyroïdienne majeure. Rev Pneumol Clin. 2012;68:315-7. https://doi.org/10.1016/j.pneumo.2012.06.001.

35. Nakielna EM, Wilson J, Ballon HS. Yellow-nail syndrome: report of three cases. Can Med Assoc J. 1976;115:46-8.

36. Danenberg HD, Eliashar R, Flusser G, Rosenmann E, Chajek-Shaul T. Yellow nail syndrome and xanthogranulomatous pyelonephritis. Postgrad Med J. 1995;71:110-1.

37. David-Vaudey E, Jamard B, Hermant C, Cantagrel A. Yellow nail syndrome inrheumatoid arthritis: a drug-induced disease? Clin Rheumatol. 2004:23: 376-8. https://doi.org/10.1007/s10067-004-0862-2.

38. Desramé J, Béchade D, Patte JH, Jean $R$, Karsenti D, Coutant $G$, et al. Syndrome des ongles jaunes associé à des lymphangiectasies intestinales. Gastroenterol Clin Biol. 2000;24:837-40 doi: GCB-08-2000-24-8-0399-8320101019-ART16.

39. Duhra PM, Quigley EM, Marsh MN. Chylous ascites, intestinal Iymphangiectasia and the 'yellow-nail' syndrome. Gut. 1985;26:1266-9.

40. Jiyad Z, Cousins E, Stanton A, Mortimer P. Yellow nail syndrome: a primary lymphatic disorder? Br J Dermatol. 2014;171(Suppl 1):9. https://doi.org/10. $1111 /$ bjd.12930

41. labal M, Rossoff $\amalg$, Marzouk KA, Steinberg HN. Yellow nail syndrome: resolution of yellow nails after successful treatment of breast cancer. Chest. 2000:117:1516-8. https://doi.org/10.1378/chest.117.5.1516.

42. Balmforth D, Bille A, Okiror L, Harrsion-Phipps K, Routledge T. Recurrent pleural effusion in yellow nail syndrome successfully treated with videoassisted thoracic surgery: comparison of two surgical strategies in two 
cases. Gen Thorac Cardiovasc Surg. 2013;61:231-3. https://doi.org/10.1007/ s11748-012-0125-0.

43. Yamagishi T, Hatanaka N, Kamemura H, Nakazawa I, Hirano Y, Kodaka N, et al. Idiopathic yellow nail syndrome successfully treated with OK-432. Intern Med. 2007;46:1127-30. https://doi.org/10.2169/internalmedicine.46.0022.

44. Widjaja A, Gratz KF, Ockenga J, Wagner S, Manns MP. Octreotide for therapy of chylous ascites in yellow nail syndrome. Gastroenterology. 1999;116:1017-8.

45. Makrilakis K, Pavlatos S, Giannikopoulos G, Toubanakis C, Katsilambros N. Successful octreotide treatment of chylous pleural effusion and lymphedema in the yellow nail syndrome. Ann Intern Med. 2004;141:246-7. https://doi.org/10.7326/0003-4819-141-3-200408030-0027.

46. Lotfollahi L, Abedini A, Alavi Darazam I, Kiani A, Fadaii A. Yellow nail syndrome: report of a case successfully treated with octreotide. Tanaffos. 2015;14:67-71

47. Hillerdal G. Yellow nail syndrome: treatment with octreotide. Clin Respir J. 2007;1:120-1. https://doi.org/10.1111/j.1752-699X.2007.00022.x.

48. Bull RH, Fenton DA, Mortimer PS. Lymphatic function in the yellow nail syndrome. Br J Dermatol. 1996;134:307-12. https://doi.org/10.1111/j.13652133.1996.tb07619.x

49. Maldonado F, Ryu JH. Yellow nail syndrome. Curr Opin Pulm Med. 2009;15: 371-5. https://doi.org/10.1097/MCP.0b013e32832ad45a.

50. D'Alessandro A, Muzi G, Monaco A, Filiberto S, Barboni A, Abbritti G. Yellow nail syndrome: does protein leakage play a role? Eur Respir J. 2001;17:149-52.

51. DeCoste SD, Imber MJ, Baden HP. Yellow nail syndrome. J Am Acad Dermatol. 1990;22:608-11. https://doi.org/10.1016/0190-9622(90)70081-R.

52. Solal-Céligny $P$, Cormier $Y$, Fournier M. The yellow nail syndrome. Light and electron microscopic Aspects of the pleura. Arch Pathol Lab Med. 1983;107:183-5.

53. Brooks KG, Echevarria C, Cooper D, Bourke SC. Case-based discussion from North Tyneside General Hospital: somatostatin analogues in yellow nail syndrome associated with recurrent pleural effusions. Thorax. 2014;69:967-8. https://doi.org/10.1136/thoraxjnl-2014-05426.

54. Cevese PG, Vecchioni R, D'Amico DF, Cordiano C, Biasiato R, Favia G, Farello GA. Post operative Chytothorax. J thorac Cardiovasc Surg. 1975;69(6):966-71.

55. Bessone LN, Fergusson TB, Burford TH. Chylothorax. Ann Thorac Surg. 1971; 12:527-50. 5.

56. Berkenbosch JW, Withington DE. Management of post operative chylothorax with nitric Oxide: a case report. Crit Case Med. 1999;27:1022-4.

57. Brenner WI, Boal BH, Reed GE. Chylothorax as a manifestation of rheumatic mitral stenosis : its postoperative management with a diet of medium chain triglycerides. Chest. 1978;73:672-3.

Ready to submit your research? Choose BMC and benefit from:

- fast, convenient online submission

- thorough peer review by experienced researchers in your field

- rapid publication on acceptance

- support for research data, including large and complex data types

- gold Open Access which fosters wider collaboration and increased citations

- maximum visibility for your research: over $100 \mathrm{M}$ website views per year

At $\mathrm{BMC}$, research is always in progress.

Learn more biomedcentral.com/submissions 